\title{
Economic Viability of Wet Season Aromatic and Non-aromatic Rice Cultivation in Dinajpur District of Bangladesh
}

\author{
Mohammad Jahangir Kabir ${ }^{1, *}$, Md Abdus Salam ${ }^{1}$, Alvira Farheen Ria ${ }^{2}$, Aabu Bakr Siddique ${ }^{1}$ \\ ${ }^{1}$ Agricultural Economics Division, Bangladesh Rice Research Institute, Gazipur, Bangladesh \\ ${ }^{2}$ Department of Environmental Science and Management, North South University, Dhaka, Bangladesh
}

Email address:

jkabirbrri@yahoo.com (M. J. Kabir), aasalam_36@yahoo.com (Md. A. Salam), alvira1902@gmail.com (A. F. Ria),

abs_63@yahoo.com (A. B. Siddique)

${ }^{*}$ Corresponding author

\section{To cite this article:}

Mohammad Jahangir Kabir, Md Abdus Salam, Alvira Farheen Ria, Aabu Bakr Siddique. Economic Viability of Wet Season Aromatic and Non-aromatic Rice Cultivation in Dinajpur District of Bangladesh. American Journal of Environmental and Resource Economics.

Vol. 5, No. 3, 2020, pp. 71-79. doi: 10.11648/j.ajere.20200503.14

Received: August 20, 2020; Accepted: September 3, 2020; Published: September 16, 2020

\begin{abstract}
The aromatic rice has cultural and economic significance in Bangladesh. This study assessed the relative economic viability (profitability and risk) of aromatic and non-aromatic wet season (WS) rice varieties. The farm-level data for this study was collected through face to face interview from Dinajpur. An enterprise, partial and stochastic budget was developed in the study. Nearly half of the total T. Aman area in the case study villages was devoted to aromatic rice, in particular modern aromatic cultivar BRRI dhan34, mainly due to it gave notable extra benefits over local aromatic (BDT. 13,519/ha) and non-aromatic (BDT. 20,197/ha) cultivars. There was no significant difference in yield between BRRI dhan34 and local aromatic variety, namely Kataribhog. However, BRRI dhan34 was found to be the more economically viable (gave higher returns and posed less risks) option due to its higher and stable market price. The higher price, guaranteed market demand, lower fertilizer requirements, shorter growth duration and suitability of late transplanting of BRRI dhan34 are the major drivers behind its widespread popularity in the region. It was clear from this research that farmers in the case study villages are highly motivated to increase adoption of the aromatic cultivar due to its price advantage and ensured market. Therefore, the development and dissemination of the higher yield potential biotic stress tolerant aromatic variety should get priority in policy planning for higher income generation and export earnings for the country.
\end{abstract}

Keywords: Aromatic Cultivars, Partial Budget, Economic Sustainability, Profitability, Risks

\section{Introduction}

Aromatic rice is widely used for cooking scented rice for religious and cultural festivals, and special family occasions. For Bangladesh, in particular, cooking exclusive dishes using this scented rice is a common phenomenon and plays an integral part in the country's social and cultural heritage. These dishes are served to entertain guests when celebrating festivals and special ceremonies. Serving scented rice to guests is even considered a matter of prestige and honour at weddings [22]. The aromatic rice has very high demand in both the domestic and international markets of wherever South Asian populations reside, be it permanent or temporary
[5]. As a result, the prices of aromatic cultivars are usually higher than that of non-aromatic varieties [3]. Furthermore, in Bangladesh, the rising GDP growth trend and observed negative elasticity, indicates that demand for the premium quality rice, non-cereal such as fish, meat, and egg tends to increase more rapidly $[19,20]$. Due to this economic importance, there is a need for increasing the adoption of aromatic rice to meet domestic and international demands [23]. However, the aromatic rice is mainly grown in the wet season, and the adoption of aromatic cultivars rice was $12.5 \%$ of total wet season rice area in Bangladesh [3] and few areas adopted by aromatic rice cultivars in the dry season in Bangladesh [2]. 
Considering the significance of the scented rice, Bangladesh Rice Research Institute (BRRI) has released seven aromatic and premium quality rice cultivars; namely, BR5, BRRI dhan34, BRRI dhan37, BRRI dhan38, BRRI dhan70, BRRI dhan 80 and BRRI dhan90 [4]. Besides, there are also a large number of local aromatic cultivars such as Kalijira, Chinigura, Kataribhog, Tulshimata, which have slender grains and pleasant aromas. Moreover, Moreover, many varieties of these desirable traits were cultivated in the various locations in the country; however, they are not familiar to people outside those areas [2]. Therefore, it has been a challenge for the country to occupy international markets for aromatic rice, since lower yield potential local cultivar aromatic rice are adopted more often, leading to a low total surplus in the country. Traditional aromatic rice could not make higher profits either, due to their lower yield. It is also important to note that coarse rice has lower market prices, and this serves as one of the most crucial obstacles for rice cultivation in Bangladesh [4]. Instead, farmers might gain more economic advantages through the practice of the new genotype of aromatic rice.

In recent times, the cultivation of modern premium quality rice serves as the light of hope to farmers since the cultivation of aromatic rice has substantial comparative advantage in the view of export and import substitution [2]. The increased adoption of aromatic rice has the potential to create new avenues of higher benefits for the farmers while at the same time, earning more foreign currency by capturing the export market. However, the profitability and risk associated with a technology and farm enterprise is largely influenced farmers' decisions to adopt the technology or crop enterprise $[12,14]$. Some studies assess the profitability and riskiness of rice/shrimp, rice/non-rice cropping system in coastal and drought-prone ecosystem [11, 13-17]. However, none of the studies found to estimate the profitability and riskiness of aromatic and non-aromatic rice in north-west Bangladesh. Thus, this study was carried out for an in-depth understanding of the economic insights of the most preferred aromatic rice. The specific objective of the study was as follows:

(i) to evaluate adoption situation of aromatic and coarse rice varieties;

(ii) to assess the relative economic viability (profitability and risk) of BRRI aromatic over other popular aromatic and coarse rice cultivars, and

(iii) to outline farmers' perceived criteria and constraints of aromatic rice cultivars.

\section{Methodology}

\subsection{Data Collection}

A multistage sampling technique was followed for selecting the areas of the study. Firstly, the Dinajpur District was selected purposefully due to the region's higher adoption of aromatic cultivars in the wet season. Secondly, Chirirbandar Upazilla was chosen based again, on their higher adoption of the aromatic variety. Thirdly, two villages such as Barogram and Basantapur were selected, as the majority of the farmers there practiced aromatic rice cultivation. Finally, sixty farmers in total, thirty from each village were selected randomly for face to face interviews during January, 2011. Besides, the farmers' perceived seasonal variability in yield and price, as well as their input use pattern data for aromatic and non-aromatic T. Aman rice was collected in 2017.

\subsection{Budgeting}

The profitability of farm enterprise can be evaluated using multiple economic tools, such as enterprise budgets, partial budgets, and whole-farm analysis. However, none of these methods can be called check-book accounting [7]. An enterprise, stochastic and partial budgeting technique were applied in the study for assessing profitability and the risk of aromatic and non-aromatic wet season rice cultivars.

\subsubsection{Enterprise Budget}

The collected data was cleaned before constructing the enterprise budget. The adoption of aromatic cultivars rice was $12.5 \%$ of the total wet season rice area in Bangladesh. The Herdt' 1978 approach, which made a vital distinction between cost items, was followed for constructing the enterprise budget. The paid-out cost is the actual cost of purchase inputs. The imputed cost is the unpaid cost of the family supplied inputs and the Gross benefit (GB) is the total value of grain and straw. Gross margin (GM) is the GB minus the Paid-out cost and the Net income is the GM minus Imputed cost [9]. The actual cost of purchase inputs hired labour, tillage, seed, fertilizer, supplementary irrigation, and insecticides was accounted as total paid-out cost. In contrast, the cost of the imputed input, such as family labour and seed was calculated using the shadow pricing approach.

\subsubsection{Partial Budget}

Partial budgeting is the most appropriate production economics analytical tool widely used for evaluating the consequences of relatively small changes in existing farms or methods. This tool is convenient to compare the profitability of alternative farm enterprises [6]. In this study, the partial budget analysis was developed to understand the economic advantage of BRRI aromatic rice cultivation over other rice varieties.

\subsubsection{Stockhastic Budget}

Cropping systems, more specifically, in the rain-fed arid and semi-arid regions, are operated under various external risks, which arise from uncertainty in weather and infestation of pest and diseases, followed by economic changes in prices of input and government and social systems [1, 18]. In the study at hand, the @ Risk software program version7.5 was used for simulating risk-return tradeoff between aromatic and non-aromatic rice in 2011 and 2017. The farmers' perceived best, normal and worst seasonal yield, as well as the maximum, most likely and lowest price of aromatic and nonaromatic rice in 2011 and 2017, were used to run the MonteCarlo simulation. In total 10,000 iteration was run for the simulation to estimate risk and return trade-off. 


\subsection{Empirical Technique}

Descriptive statistics was used to analyzing the data. Tabular and graphical techniques were used for presenting the outcome as mean and percentage etc.

Application of Independent t-Test for Mean Difference for dominant aromatic and non-aromatic Rice

$$
\sigma\left(X_{1}-X_{2}\right)={\sqrt{\left(\sigma_{x 1}\right)}}^{2}+{\sqrt{\left(\sigma_{x 2}\right)}}^{2}
$$

and $\sigma_{\mathrm{x}}=\frac{\sigma_{x}}{\sqrt{n}}$

where

$\sigma\left(X_{1}-X_{2}\right)=$ The standard error of difference between means $\sigma_{X}=$ Standard error

$n=$ sample size

We have to see whether or not the actual difference exceeds $2 \sigma\left(X_{1}-X_{2}\right)$. If it does not, the population means are most unlikely to be same. In statistical jargon, it should be said that the difference between the means is significant at the $95 \%$ level of confidence and therefore the population does not have the same mean [8].

\section{Results and Discussion}

\subsection{Aromatic Rice Production Situation}

In the wet season, the Indian variety Swarrna was a dominant T. Aman rice variety, in addition to the coarse rice varieties BR11, Pajam, BRRI dhan33, BRRI dhan30, BRRI dhan32 and BRRI dha40 in the case study villages. The farmers of the villages also mainly grew some potential aromatic rice varieties such as BRRI dhan34 and the local aromatic variety Kataribhog. The survey revealed that the average farm size of the respondent farmers was 2.43 hectares. On average $75 \%$ (e.g., 1.81 hectares) of total arable land in the study villages was devoted to T. Aman rice cultivation. Farmers in the villages cultivate coarse rice for family subsistence, while they grow aromatic rice mainly as a cash crop. The adoption rate of aromatic rice was over half $(53 \%)$ of the total T. Aman rice area, of which the adoption rate of BRRI dhan 34 was a major ( $66 \%$ of total aromatic area) variety and gave higher yield and return. On the other hand, the adoption of the Indian cultivar named Swarna was the most popular $(69 \%)$ among the coarse rice cultivars. A key finding of this study is that the farmers in these villages allocate a notable percent of $\mathrm{T}$. Aman rice area for aromatic rice cultivation, indicating that rice cultivation in the area is not merely subsistence-oriented, but rather semi-subsistence farming.

\subsection{Profitability of Aromatic and Non-aromatic Rice}

\subsubsection{Input Use Pattern}

The survey revealed that the farmers used both familysupplied and purchased inputs for monsoon rice cultivation in the survey area, but relied less on the family-supplied inputs. Farmers mainly used household seeds and family labour for low labour intensive operations such as land preparation, weeding and post-harvest processing. This indicates that farmers in these areas are mostly dependent on the hired labour, two-wheel power tractor, power thresher and inputs (fertilizers and pesticides) needed for rice cultivation.

Table 1 presents human labour and input use pattern of aromatic and non-aromatic (coarse) rice cultivations in Dinajpur. There was no large variation between per hectare human labour employed for the intercultural operations of aromatic (110 and 111 man-days for Kataribhog and BRRI34, respectively) and non-aromatic rice (119 man-days) cultivation. Furthermore, the participation of hired labour for intercultural operations was very high in the case of coarse rice. Although, the rate of application of other inputs, in particular seeds and fertilizers, was considerably higher in non-aromatic rice (seed $50 \mathrm{~kg} / \mathrm{ha}$ and fertilizers $284 \mathrm{~kg} / \mathrm{ha}$ ) than that of aromatic (seed 39-42 kg/ha and fertilizers 189$197 \mathrm{~kg} / \mathrm{ha}$ ) rice cultivation. Besides, there was not much difference between the seed and fertilizer use of BRRI dhan34 and popular local aromatic cultivar Kataribhog.

However, the farmers' practiced seed rates were found to be largely higher than that of BRRI recommendation, irrespective of both aromatic and non-aromatic rice. This may be because of the low germination of household seeds and/or lack of knowledge on recommended seed rates. Also, the amount of fertilizer applied by farmers in aromatic rice was nearly half of what BRRI's recommends (Urea-165-195, TSP-60, MP-105-135, gypsum-68), and the fertilizer applied for non-aromatic coarse rice was much lower than the BRII recommendations. Besides, farmers applied higher doses of fertilizer for coarse rice $(284 \mathrm{~kg} / \mathrm{ha})$ than that of aromatic rice (189-197 kg/ha) (Table 1; [3]). Similarly, reported this observation as well, stating that farmers applied notably higher amounts of fertilizers for coarse rice $(257 \mathrm{~kg} / \mathrm{ha})$ than that of aromatic (113 kg/ha) rice [10]. These results indicate that the aromatic rice cultivars are considerably less fertilizer intensive than non-aromatic coarse rice cultivars. Moreover, farmers apply less fertilizer than what is recommended, irrespective of aromatic and non-aromatic cultivars.

Table 1. Per hectare labour and inputs use pattern of aromatic and coarse monsoon rice cultivation in Dinajpur.

\begin{tabular}{llll}
\hline \multirow{2}{*}{ Items } & \multicolumn{2}{l}{ Aromatic } & $\begin{array}{l}\text { Non-Aromatic } \\
\text { Coarse }\end{array}$ \\
\cline { 2 - 3 } & Kataribhog & BRRI dhan 34 & Swarna \\
\hline Human labor (man-days): & 111 & 110 & 119 \\
Family & 19 & 20 & 21 \\
Hired & 92 & 90 & 98 \\
Seed (Kg): & 42 & 39 & 50 \\
Owned & 36 & 35 & 44 \\
Purchase & 6 & 4 & 6 \\
Fertilizer (Kg): & 189 & 197 & 284 \\
Urea & 76 & 75 & 113 \\
TSP & 36 & 47 & 75 \\
MP & 50 & 50 & 58 \\
Gypsum & 23 & 21 & 33 \\
ZnSo & 4 & 4 & 5 \\
Farm yard manure (kg) & 1,734 & 1,968 & 2,107 \\
Owned & 1,127 & 1,181 & 1,306 \\
Purchase & 607 & 787 & 801 \\
\hline
\end{tabular}

Source: Farm household survey, 2011. 


\subsubsection{Cost Structure}

Table 2 shows the per hectare cost of aromatic and nonaromatic coarse rice production in Dinajpur. The per hectare total paid-out cost (TPC) of the coarse variety Swarna was higher than that for aromatic rice cultivation. Similarly reported that the total variable cost (TVC) coarse rice (BST $10,332 / \mathrm{ha}$ ) was higher than that of aromatic (BDT 9,225/ha) rice [10]. It was observed that the per hectare TPC of aromatic varieties (for BRRI dhan34 and Kataribhog) were consistent; and that the per hectare total imputed cost (TIC) of coarse and aromatic rice were consistent as well. Another finding was that per hectare fertilizers and hired labour cost for coarse rice were higher than that for both the aromatic cultivars. These results indicate that the aromatic cultivars are less fertilizer and labour intensive than the coarse cultivar

Table 2. Per hectare costs (BDT) of aromatic and coarse monsoon rice cultivation in Dinajpur.

\begin{tabular}{llll}
\hline \multirow{2}{*}{ Cost items } & \multicolumn{2}{l}{ Aromatic } & Coarse \\
\cline { 2 - 4 } & BRRI dhan34 & Katarinbough Swarna \\
\hline Total paid-out cost (BDT/ha): & 27,948 & 26,915 & 31,160 \\
Land rent & 2,270 & 1,783 & 2,339 \\
Tillage & 3,826 & 4,136 & 3,990 \\
Seed and seedling raising & 3,162 & 2,693 & 2,726 \\
Hired labour & 13,319 & 13,664 & 14,789 \\
\hline
\end{tabular}

\begin{tabular}{llll}
\hline \multirow{2}{*}{ Cost items } & Aromatic & & Coarse \\
\cline { 2 - 4 } & BRRI dhan34 & Katarinbough Swarna \\
\hline Fertilizers & 4,251 & 3,519 & 5,985 \\
Pesticides & 900 & 940 & 1,143 \\
Herbicide & 220 & 180 & 188 \\
Total imputed cost (BDT/ha): & 14,791 & 14,886 & 14,282 \\
Household seed & 519 & 756 & 404 \\
Family labour & 2,924 & 2,778 & 2,282 \\
Household farm yard manure & 866 & 389 & 1,127 \\
Own land rent & 9,954 & 10,458 & 9,885 \\
Interest on operating capital & 528 & 505 & 584 \\
Total cost (BDT/ha): & 42,739 & 41,801 & 45,442 \\
\hline
\end{tabular}

Source: Farm household survey, 2011.

Figure 1 displays the representation of different inputs in the total cost of cultivation of aromatic and coarse rice varieties. The TPC of aromatic and non-aromatic rice cultivars ranges between $60-63 \%$ of total cost cultivation. The representation of inputs in the per hectare total production cost was the highest for hired labour (31-33\%), followed by land rent $(27-29 \%)$, fertilizers $(9-13 \%)$ and tillage (9-10). Likewise reported that the per hectare human labour cost (BDT 3,236/ha) in TVC/ha of rice cultivation was considerably higher than others, followed by fertilizers (BDT 2,759/ha) and tillage (BDT 2,267/ha) cost [10].

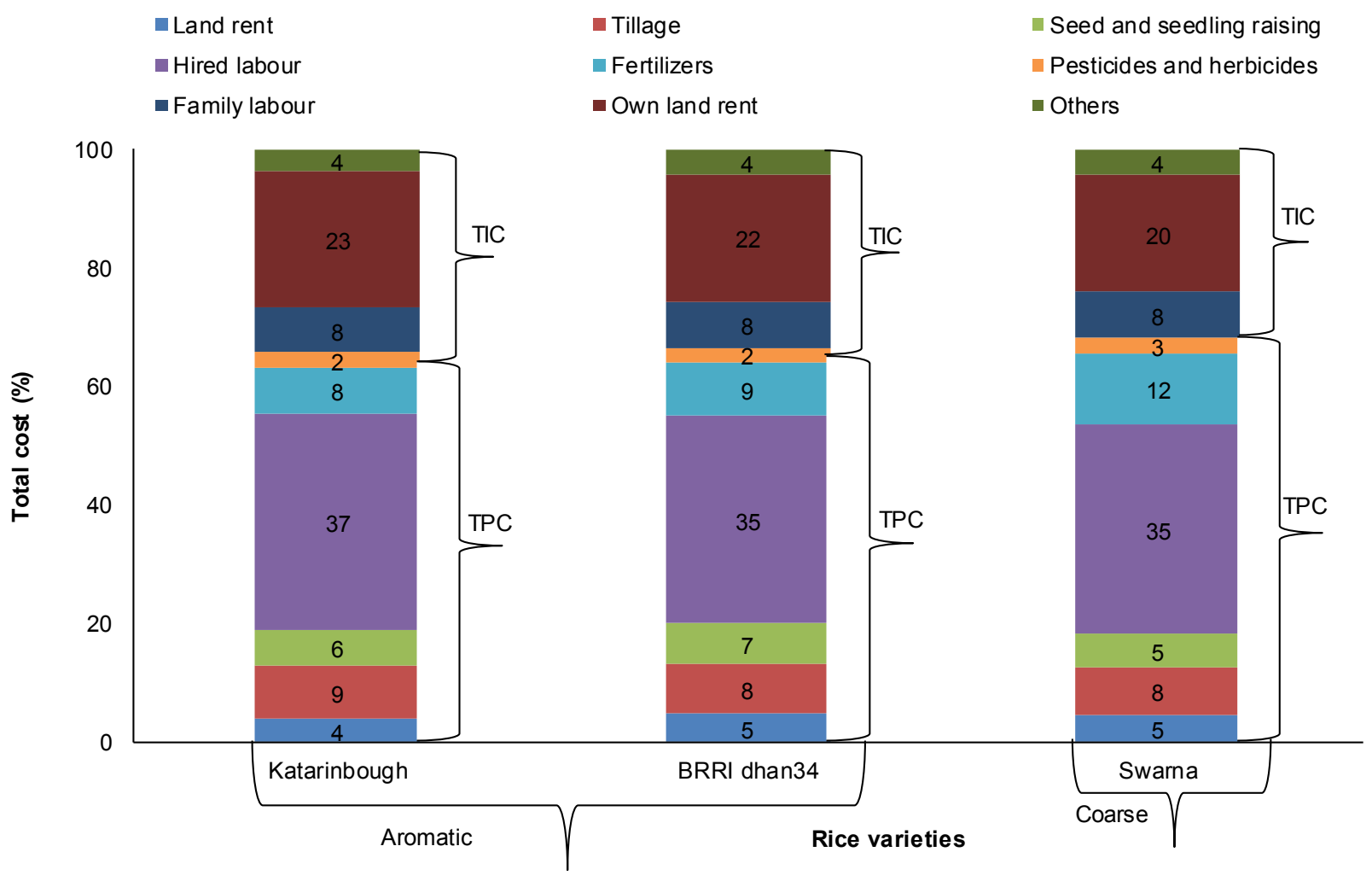

Note: TIC: Total imputed cost TPC: Total paid-out cost.

Figure 1. Representation of inputs in total cost of production in Dinajpur.

\subsubsection{Yields and Returns}

Table 3 shows the per hectare yields and returns of aromatic and coarse rice cultivation in Dinajpur. The per hectare yields of local aromatic varieties such as Kataribhog and BRRI aromatic varieties such as BRRI dhan34 were consistent. However, the per hectare yield of the coarse variety Swarna $(3.8 \mathrm{t} / \mathrm{ha})$ was largely higher than that of Kataribhog (2.7 t/ha) and BRRI dhan34 (2.6 t/ha). It was 
found that the farmers obtained 29 and 31 percent less yield than BRRI dhan34 and Kataribhog, respectively, compared to the popular 'Swarna' (Table 5). It was also revealed that the average yield benefit of the aromatic Swarna variety was 1.2 t/ha and $1.1 \mathrm{t} / \mathrm{ha}$, compared to that of BRRI dhan34 and Kataribhog, respectively. Likewise, reported that per hectare yield of course rice $(3.4 \mathrm{t} / \mathrm{ha})$ was higher than that of aromatic rice (1.6 t/ha) [10]. However, despite these, higher yields, the per hectare returns of coarse variety monsoon rice was largely lower than aromatic variety monsoon rice (Table 2 and 3). This is due to the lower cost of cultivation and higher grain of price of aromatic rice.

The per hectare gross income of BRRI dhan34 (BDT $69,760 \mathrm{t} / \mathrm{ha}$ ) and Kataribhog (BDT 55,882/ha) were considerably higher than that of Swarna (BDT 50,251/ha), mainly because of the higher grain price of BRRI dhan 34 and Kataribhog. Similarly, the net income of BRRI dhan34 (BDT $52,427 /$ ha) was also higher followed by Kataribhog (BDT $39,295 / \mathrm{ha}$ ) and Swarna (BDT 33,835/ha). The results indicate that BRRI dhan34 is not only a profitable farm enterprise but also an important source of cash income for the rural farm households (Table 3).
Table 3. Per hectare yields and returns of aromatic and non-aromatic coarse monsoon rice cultivation in Dinajpur.

\begin{tabular}{llll}
\hline \multirow{2}{*}{ Yield and returns } & Aromatic & & Coarse \\
\cline { 2 - 4 } & BRRI dhan34 & Kataribhog & Swarna \\
\hline Yield (t/ha): Grain & 2.6 & 2.7 & 3.8 \\
Straw & 2.2 & 2.3 & 3.2 \\
Value of grain & 91,490 & 76,836 & 73,613 \\
Value of straw & 3,921 & 4,023 & 4,813 \\
Paddy price (BDT/kg) & 35.0 & 28.5 & 19.5 \\
Gross benefit (BDT/ha) & 95,411 & 80,859 & 78,426 \\
Gross income (BDT/ha) & 69,760 & 55,882 & 50,251 \\
Net income (BDT/ha) & 52,427 & 39,295 & 33,835 \\
\hline
\end{tabular}

\subsubsection{Statistical Significance of Differences in Costs and Returns}

Table 4 presents the mean difference of major cost items, cost and returns between BRRI dhan34 and Kataribhog. It was found that there was no significant difference in the per hectare fertilizers, pesticides and human labour cost of BRRI dhan 34 and Kataribhog. However, there was a significant mean difference in the paid-out cost, total cost, gross return and net return per hectare of BRRI dhan 34 and Kataribhog. The results indicate BRRI dha34 incurred higher costs and gave significantly higher returns than Kataribhog.

Table 4. Mean difference t-vale between BRRI dhan 34 and Kataribhog.

\begin{tabular}{|c|c|c|c|c|c|}
\hline Data & BRRI dhan 34 & Kataribhog & Mean difference & t-value & $\mathbf{P}(\mathbf{T}<=\mathbf{t})$ \\
\hline Seed (BDT/ha) & 3,162 & 2,693 & $469^{\text {ns }}$ & 0.83 & 0.206 \\
\hline Fertilizer cost $(\mathrm{BDT} / \mathrm{ha})^{2}$ & 4,251 & 3,519 & $732^{\mathrm{ns}}$ & 0.692 & 0.247 \\
\hline Cost of pesticides (BDT/ha) & 900 & 940 & $-40^{\mathrm{ns}}$ & -0.813 & 0.212 \\
\hline Labour cost (BDT/ha) & 16,243 & 16,442 & $-199^{\mathrm{ns}}$ & -0.573 & 0.285 \\
\hline Total Paid-out cost (BDT/ha) & 27,948 & 26,915 & $1,033^{*}$ & 5.315 & 0.000009 \\
\hline Total cost (BDT/ha) & 42,739 & 41,801 & 938 & 1.429 & 0.082 \\
\hline Net income (BDT/ha) & 52,427 & 39,295 & $13,132 * * *$ & 3.88 & 0.0003 \\
\hline
\end{tabular}

****, * indicates significant at $1 \%$ and $10 \%$ level.

Table 5 presents the mean difference of major cost items, cost and returns between BRRI dhan34 and Swarna. It was found that BRRI dhan34 incurred significantly lower cost for fertilizers, as well as total cost, compared to Swarna. However, gross return and net return per hectare of BRRI dhan 34 was significantly higher than Swarna. The results indicate BRRI dha34 incurred lower cost, but gave significantly higher returns than Swarna.

Table 5. Mean difference t-vale between BRRI dhan 34 and Swarna.

\begin{tabular}{|c|c|c|c|c|c|}
\hline Data & BRRI dhan 34 & Swarna & Mean difference & t-value & $P(T<=t)$ \\
\hline Seed (BDT/ha) & 3162 & 2,726 & $436 * * *$ & 3.14 & 0.0013 \\
\hline Fertilizer (BDT/ha) & 4251 & 5,985 & $-1,734 * * *$ & -4.12 & 0.00005 \\
\hline Pesticides (BDT/ha) & 900 & 1,143 & $-243^{\text {ns }}$ & -0.084 & 0.467 \\
\hline Labour cost (BDT/ha) & 16243 & 17,071 & $-828^{\text {ns }}$ & -0.912 & 0.365 \\
\hline Total paid-out cost (BDT/ha) & 27948 & 31,160 & $-3,212 *$ & -1.87 & 0.032 \\
\hline Total cost (BDT/ha) & 42739 & 45,442 & $-2,703^{*}$ & -1.933 & 0.0289 \\
\hline Net income (BDT/ha) & 52427 & 33,835 & $18592 * *$ & 2.95 & 0.0024 \\
\hline
\end{tabular}

$* * * *, * *, *$ indicates significant at $1 \%, 5 \%$ and $10 \%$ level.

\subsubsection{Partial Budget Analysis}

Partial budget analysis was done to assess the breakdown of the economic advantage of BRRI dhan34 over Swarna rice. Results of the partial budget analysis between BRRI dhan34 and Swarna rice cultivation indicated that BRRI dhan34 producers could earn an extra benefit of BDT. 20,197/ha by cultivating BRRI dhan34 rice instead of cultivating Swarna (Table 6).

In the same way, the partial budget analysis was done to assess the breakdown of the economic advantage of BRRI dhan34 over Kataribhog rice, under the aromatic group. Results of the partial budget analysis between BRRI dhan34 and Kataribhog rice cultivation indicated that BRRI dhan34 
producers could earn an additional benefit of BDT. 13,519/ha by cultivating BRRI dhan34 rice instead of cultivating Kataribhog (Table 7). Likewise, reported that aromatic rice gave higher income than that of non-aromatic rice cultivars in Tangial district in Bangladesh [21].

Table 6. Partial budgeting for BRRI dhan34 versus Swarna rice production T. Aman Wet Season.

\begin{tabular}{lll}
\hline \multirow{2}{*}{ Items } & \multicolumn{1}{c}{ Debit (BDT/ha) } & Items \\
\cline { 2 - 2 } & BRRI dhan 34 & \\
\hline A. Cost of producing BRRI 34 & 27,948 & A. Cost saved for cultivating Swarna \\
B. Revenue forgone for not growing Swarna & 78,426 & B. Revenue earned from producing BRRI 34 \\
C. Profit & 20,197 & 95,411 \\
Total & 126,571 & \\
\hline
\end{tabular}

Table 7. Partial budgeting for BRRI dhan34 versus Kataribhog rice production in T. Aman Wet Season

\begin{tabular}{lll}
\hline \multirow{2}{*}{ Items } & Debit (BDT/ha) & \multirow{2}{*}{ Items } \\
\cline { 2 - 3 } & BRRI 34 & Kataribhog \\
\hline A. Cost of producing BRRI 34 & 27,948 & A. Cost saved for cultivating Kataribhog \\
B. Revenue forgone for not growing Kataribhog & 80,859 & B. Revenue earned from producing BRRI 34 \\
C. Profit & 13,519 & \\
Total & 122,326 & \\
\hline
\end{tabular}

\subsubsection{Risk Analysis}

Figure 2 demonstrates the cumulative probability distribution (CDFs) of aromatic and non-aromatic rice in 2011. The lower boundary of CDFs was zero, indicating that net income lower than zero is a total loss; and the upper boundary was selected randomly (BDT 20,000). CDF of BRRI developed aromatic cultivar BRRI dhan34 shows that there is first-degree stochastic dominance over local cultivar aromatic cultivar Katatibough and the most dominant non- aromatic cultivar Swarna, while the Kataribhog sows displays second-degree stochastic dominance over Swarna. The results of the risk analysis indicate that the probability of receiving negative net income for $\mathrm{T}$. Aman rice was zero at farmers' perceived variability in yield and price in 2011. It also revealed that BRRI dhan34 has about $100 \%$ chance of giving net income over BDT 20,000 per ha, which decreases to $80 \%$ for Kataribhog and $73 \%$ for Swarna. These results indicate that BRRI dhan34 was economically more viable followed by Kataribhog and Swarna.

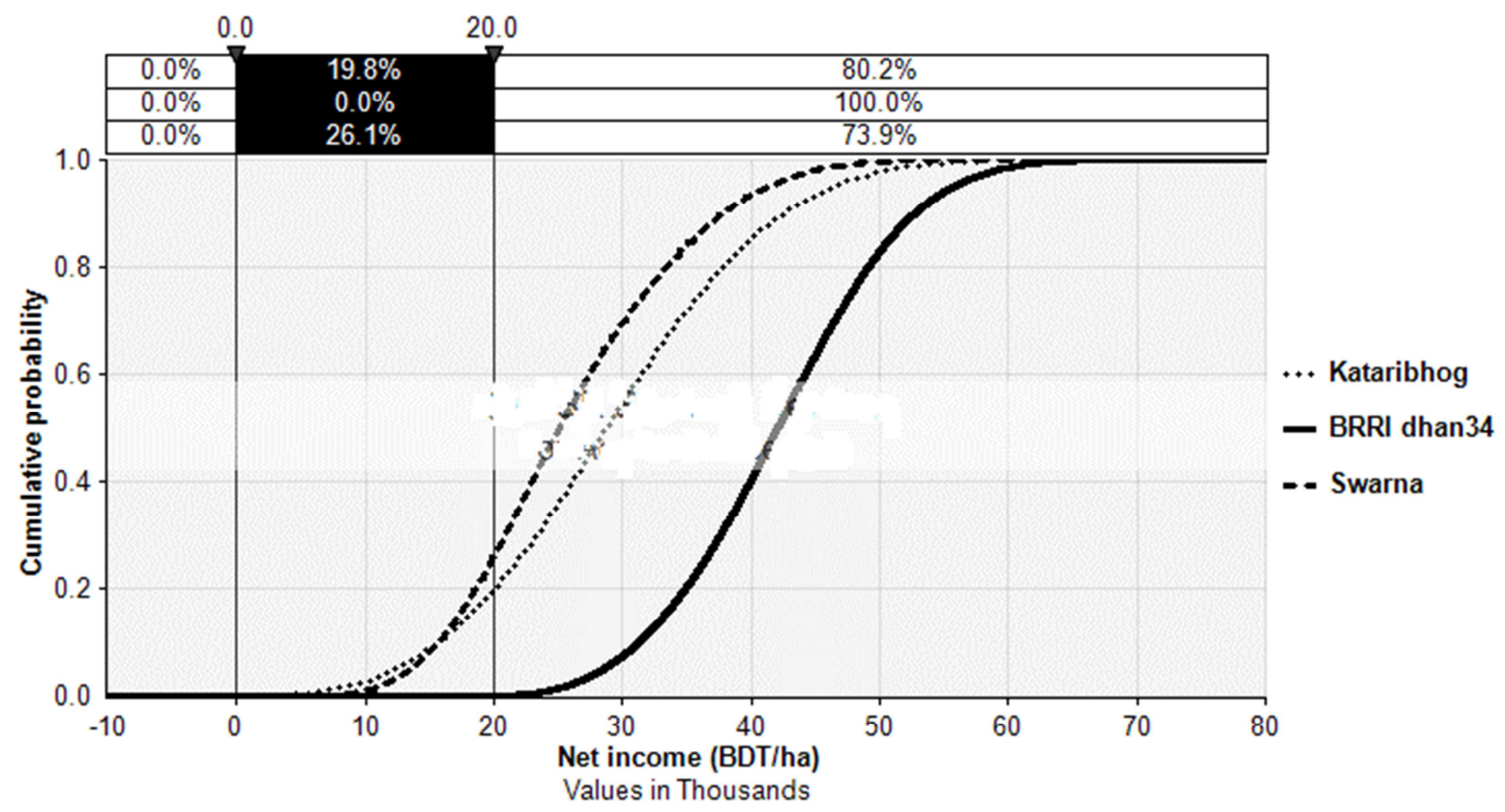

Figure 2. Cumulative probability distribution of net income of aromatic and non-aromatic rice in 2011.

Figure 3 presents the cumulative probability distribution (CDFs) of aromatic and non-aromatic rice in 2017. The lower boundary of CDFs was zero, indicating that net income lower than zero is a total loss. The upper boundary was selected randomly (BDT 28, 500). CDF of BRRI developed aromatic cultivar BRRI dhan34 shows first-degree stochastic dominance over local aromatic cultivar Kataribhog and most dominant non-aromatic cultivar Swarna. The CDFs shows that both Kataribhog and Swarna have in range between 20$23 \%$ probabilities of giving negative net income. On the 
contrary, the probability of having negative net income for BRRI dhan34 was not only nil, but also, the chance of having net income over the upper boundary (BDT 28,500) was $76 \%$. The key insight of the risk analysis is that the risk of coarse cultivars increased over time, while the risk of aromatic cultivar BRRI dhan34 is observed stable (Figure 3). It indicates that BRRI dhan34 was economically more viable than that of Kataribhog and Swarna.

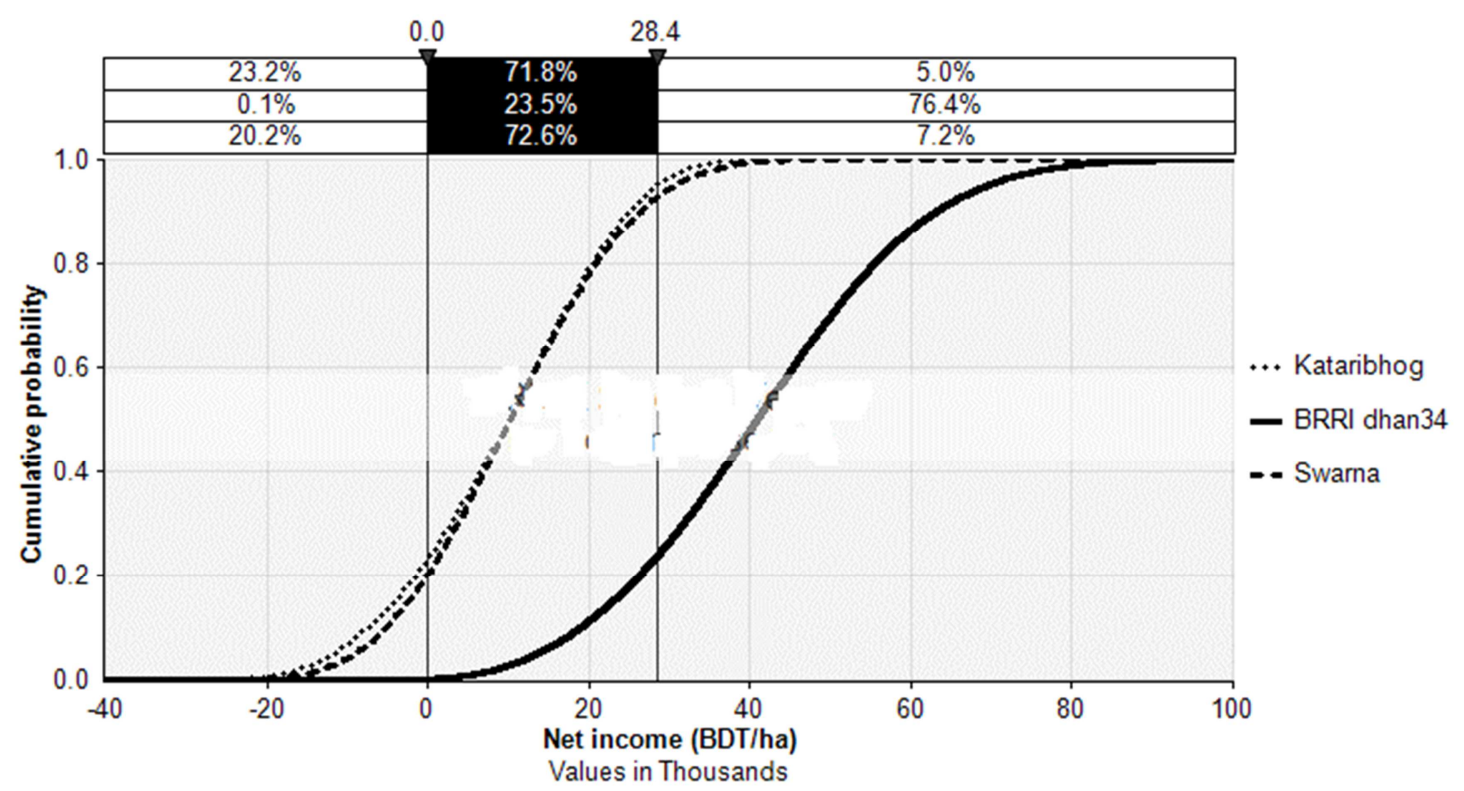

Figure 3. Cumulative probability distribution of net income of aromatic and non-aromatic rice in 2017.

\subsection{Criteria and Constraints to Adoption of BRRI Dhan34}

Table 8 shows the major criteria of adoption BRRI dhan34. Higher return due to (i) the higher price and ensured market demand, and (ii) less fertilizer intensive farming, are the key economic criteria of adoption BRRI dhan34 reported by the most respondent farmers (70-100\%). 3.5 It can be noted that farmers usually produce aromatic rice for commercial purposes as they get a higher return from it. The survey results revealed that average per farm production of aromatic rice was 2.65 tons, of which only 5 percent was used for home consumption and the rest (95\%) was sold.

The social criteria (in particular of scented rice) of BRRI dhan34 is the fact that it is the most favorite dish in the religious and cultural festivals, and this also an important criterion in favour of the adoption of the variety, as reported by $63-100 \%$ of total sample respondents. Furthermore, the key agronomic drivers of adoption of BRRI dhan34 are the suitability for delayed planting, shorter growth duration and less lodging, as reported by $43-93 \%$ of total respondents (Table 8).

The major agronomic constraints of adoption of BRRI dhan34 included higher susceptibility to biotic (e.g., pest) and abiotic (droughts) stresses, reported by $57-83 \%$ of total farm households. More labour requirements for double transplanting and higher yield sensitivity about the time of fertilizers and pesticides application were also reported by farmers as constraints to the cultivation of BRRI dhan34 (Table 8).

Table 8. Major criteria and constraints of adoption BRRI dhan34 in Dinajpur.

\begin{tabular}{llll}
\hline Factors & Criteria & Frequency (n=60) & \% of response \\
\hline \multirow{3}{*}{ Economic } & Higher demand and price & 30 & 100 \\
& Profitable & 30 & 100 \\
& Less fertilizer intensive & 21 & 70 \\
Social & Reasonable yield & 11 & 37 \\
& Favorite rice for festival & 30 & 100 \\
& Good for scented rice & 19 & 63 \\
Agronomic & Suitable for late planting & 28 & 93 \\
& Less lodging & 14 & 47 \\
& Shorter lifecycle & 13 & 43 \\
& Availability seed & 8 & 27 \\
Agronomic & Constraints & & 83 \\
& Higher insects and diseases infestation & 25 \\
\hline \multirow{2}{*}{ Economic } & Drought susceptible & 17 \\
\hline
\end{tabular}




\section{Conclusion}

The study revealed that the cultivation of aromatic rice is more profitable at farm level than coarse rice, even with its lower yield than the non-aromatic coarse rise in wet season. Among the two aromatic varieties, BRRI dhan34 was more profitable than the local aromatic Kataribhog. The yield benefit of coarse rice could not earn a higher profit than aromatic varieties because of the higher price of aromatic BRRI dhan34 rice cultivars. The study also indicates that farmers are highly motivated to increase the adoption of BRRI dhan34, as the cultivar was profitable and less risky because of its higher price and ensured market demand. The risk of coarse cultivars increased over time, while the risk of aromatic cultivar BRRI dhan34 remained stable. Along with the taste preference of the consumers, the aromatic cultivars have good potential in the international markets. However, the higher seasonal variation in the price of non-aromatic rice, the severe sensitivity to the pest of both aromatic and nonaromatic cultivars are the major constraints for large scale dissemination of aromatic rice and sustainability for coarse rice. Thus, the development and dissemination of higher yield potential biotic stress tolerant aromatic cultivars, as well as access to the export market should get priority in policy planning for the wellbeing of farm households.

\section{References}

[1] Anderson, J. R., Dillon, J. L., \& Hardaker, J. B. (1988). Agricultural Decision Analysis (Third ed.). Iowa, USA: Iowa State University Press.

[2] Anik, A. R. and Talukder, R. K. (2002). Economic and Financial profitability of Aromatic and Fine Rice Production in Bangladesh, Bangladesh Journal of Agricultural Economics, 25 (2), 103-113.

[3] BRRI. (2017). Yearbook of Agricultural Statistics of Bangladesh 2014. Dhaka, Bangladesh: Bangladesh Bureau of Statistics (BBS), Ministry of Planning, Government of the People's Republic of Bangladesh.

[4] BRRI (2019). Annual Report 2017, Bangladesh Rice Research Institute (BRRI), Gazipur, Bangladesh.

[5] Das, T. and Baqui, M. A. (2000). Aromatic Rice of Bangladesh. In: Aromatic Rice. Oxford and IBH Publishing Co. Pvt. Ltd., New Delhi.: 184-187.

[6] Dillon, J. L., \& Hardaker, J. B. (1993). Farm Management Research for Small Farmer Development (Vol. 6). Rome, Italy: Food and Agriculture Organization of the United Nations (FAO).

[7] Dillon, C. R. (2003). A Framework for Economic Analysis of Cropping Systems: Profitability, Risk Management, and Resource Allocation. Journal of Crop Production, 9 (1-2), 409432 .

[8] Harper W. M (1977). Statistics Book, Macdonald and Bungay, Evans, Suffolk, USA.

[9] Herdt, R. W. (1978). Costs and Returns for Rice Production
Economic Consequences of the New Rice Technology (pp. 63). International Rice Research Institute (IRRI), Los Banos, Philippines.

[10] Islam, M. (2002) "Determinants of Production and Demand for Rice in Bangladesh: Comparative Study of Aromatic and Coarse varieties", PhD thesis, Submitted to the Faculty of Agricultural Economics and Rural Sociology, Bangladesh Agricultural University, Mymensingh, Bangladesh.

[11] Kabir, J., Cramb, R., Alauddin, M., Gaydon, D. S. and Roth, C. H. (2020). Farmers' perceptions and management of risk in rice/shrimp farming systems in South-West Coastal Bangladesh. Land Use Policy, 95, p. 104577.

[12] Kabir, M. J. (2016). The Sustainability of Rice-Based Cropping Systems in Coastal Bangladesh: Bio-Economic Analysis of Current and Future Climate Scenarios. PhD thesis, Submitted to Graduate School, The University of Queensland, Australia.

[13] Kabir, M. J., Alauddin, M., and Crimp, S. (2017a). Farm-level adaptation to climate change in Western Bangladesh: An analysis of adaptation dynamics, profitability and risks. Land Use Policy, 64, 212-224.

[14] Kabir, M. J., Cramb, R., Alauddin, M., and Gaydon, D. S. (2019). Farmers' perceptions and management of risk in ricebased farming systems of south-west coastal Bangladesh. Land Use Policy, 86, 177-188.

[15] Kabir, M. J., Cramb, R., Alauddin, M., and Roth, C. (2016). Farming adaptation to environmental change in coastal Bangladesh: shrimp culture versus crop diversification. Environment, Development and Sustainability, 18 (4), 11951216.

[16] Kabir, M. J., Cramb, R., Gaydon, D. S., and Roth, C. H. (2017b). Bio-economic evaluation of cropping systems for saline coastal Bangladesh: II. Economic viability in historical and future environments. Agricultural Systems, 155, 103-115.

[17] Kabir, M. J., Cramb, R., Gaydon, D. S., and Roth, C. H. (2018). Bio-economic evaluation of cropping systems for saline coastal Bangladesh: III Benefits of adaptation in current and future environments. Agricultural Systems, 161, 28-41.

[18] McConnell, D. J., \& Dillon, J. L. (1997). Farm Management for Asia: a Systems Approach. Rome, Italy: Food and Agriculture Organization of the United Nations (FAO).

[19] Murshid, K. A. S., Islam, M. N., Shahabudddin, Q., Akter, M. Y. S. and Chowdhury, O. H. (2008). Determination of Food Availability and Consumption Pattern and Setting Up of Nutritional Standard in Bangladesh, Bangladesh Institute of Development Studies, Maxwell Stamp in collaboration with Food Planning and Monitoring Unit (FPMU) Ministry of Food and Disaster management \& National Food Policy Capacity Strengthening Programme (NFPCSP) and FAO.

[20] Salam, M. A., J. Furuya, and S. Kobayashi (2016a). Climate Effect on Supply and Market Price Stability of Rice in Bangladesh: Assessment of Climate and Socioeconomic Scenarios, Japanese Journal of Agriculture Economics (JJAE) 19: 60-65.

[21] Nasrin J. and Uddin M. T. (2013). Financial profitability of aromatic rice production and its impact on farmers' livelihood in selected areas of Tangail District. Bangladesh Journal of Political Economy, 29 (1), pp. 45-59. 
[22] Tama, R. A. Z., Ismat Ara Begum, I. A., Alam, M. J. and, and Islam, S. (2015). Financial Profitability of Aromatic Rice Production in Some Selected Areas of Bangladesh, International Journal of Innovation and Applied Studies Vol. 12 (1): 235-242.
[23] Trang, T. H. T. and Napasintuwong, O. (2016). Farmers' willingness-to-change and adoption of aromatic rice in Vietnam. Journal of ISSAAS (International Society for Southeast Asian Agricultural Sciences), 22 (2), pp. 50-65. 